\section{Breakout session one: summary of delegates' discussions}

What research topics can the group recommend in order to:-

a) Inform the planning and development of the LIS sector nationally, regionally and locally?

b) Develop, innovate and improve professional practice?

c) Develop areas of knowledge that are poorly understood?

There was recognition of sufficient change in the following existing areas of practice and knowledge that require a new approach.

\section{User behaviour}

\section{(See also Information literacy)}

How do $21^{\text {st }}$ century information seekers search and what information do they use?

Is our information organisation appropriate for (these assumed) new behaviours?

\section{Information literacy (See also User behaviour)}

What models of information literacy are appropriate for the $21^{\text {st }}$ century?

Are we working with outdated models?

\section{The role of the LIS professional in the} changing information environment

What are the current and future roles for LIS professionals?

What role do information users expect with regard to information storage, information retrieval, information dissemination?

What role do users expect with regard to their use of IT based information, learning and research environments?

\section{The nature and use of information by differing groups of users}

What understanding do we have of the difference in information user behaviour for the following groups?

- Communities searching public information or information for use within a local or regional area.

- Professional groups

- Organisations including businesses of all sizes

- Government and other agencies

- Sectors especially: - business; schools; health; knowledge industry.

- Age groups: - young people, old people, working people.

\section{The LIS workforce}

(See also The role of the LIS professional)

Are we producing professionals that meet the challenge of the new information environments?

\section{Use of new and emerging technologies for greatest positive impact}

How do we disseminate good practice in the potential for Web 2.0, 'Yutube' or 'MySpace'?

\section{The $2 I^{\text {st }}$ century information environment}

What understanding do we have of the impact of design of real and virtual information environments?

What principles should influence our creation of Virtual Information Environments?

What principles should influence library building design?

\section{The role of the $2 I^{\text {st }}$ century library}

Establishing a role for the organisation of information required by society within the Public Library context.

Establishing a role for the capture of and access to information created by publicly funded research within the University context. 


\section{The knowledge economy}

How do we grow awareness and understanding of an organisation's need of knowledge transfer?

What are the expectations of Library and Information Professionals in their organisation's management of their business critical intangible assets including knowledge capture, intellectual capacity and intellectual property?

\section{What do we need to know and what tools do we need in order to extend LIS research?}

What are the national and regional agendas that LIS Professionals should $\mathrm{b}$ e responding to?

What is the evidence base?

What are the data resources required?

How does LIS Professional continue to create data and extend its use in longitudinal studies, case studies and evidence based activity?

\section{Outcomes}

A research agenda that will:-

Balance pure (blue skies) and applied (practitioner led) activity.

Inform and impact on the professional practice of service delivery.

Engender dissemination, debater and communication.

Utilise existing and promote new partnerships especially non- textual information creators.

Motivate practitioner and academic collaboration and establish more tangible relationships.

Harness new technologies and new social networking tools.

Answer the questions that create Government agendas.

This research activity will involve:-

A data centric approach.

Permitting advocacy using evidence.

Supporting professional practice with an evidence base.

Growing an appreciation of research methodologies for use in investigations at local level.
Establishing a sound foundation for the use of user studies, case studies, and systematic reviews.

\section{Some useful comments and suggestions for achieving the above}

Develop the 'observatory' concept.

Promote awareness of systematic reviews.

Create the generalisable and more tangible researcher /practitioner relationships.

Extend the scope of JOLIS/JIS update.

Involve communities in developing understanding of their behaviours.

LIS Professionals need to know how to:

- Apply methodologies

- Create appropriate partnerships for information creation, use and sharing

- Apply appropriate standards

- Use evidence in promotion, marketing and advocacy.

The profession must:-

- Establish a forum in order to articulate and co-ordinate the creation of a research agenda

- Promote exploration of both local and regional agendas where LIKS contribution would enhance outcomes

- Develop capacity, critical mass and skills to create a new momentum

- Retain data collection to ensure a data centric approach.

\section{Rocks and hard places: chickens and eggs}

No debate between researchers and practitioners: no clear directions for research.

No lead on research strategy: a void in activity. Insufficient skills too thinly spread: no impetus for starting and continuing research activity. 